\title{
Execution of Plastic Parts Using 3D Scanners and 3D Printers
}

\begin{abstract}
ANCA BUCURESTEANU ${ }^{1}$, DAN PRODAN ${ }^{1}$, ADRIAN MOTOMANCEA ${ }^{2 *}$
${ }^{1}$ University Politehnica of Bucharest, Department of Machines and Production Systems, 313 Splaiul Independenei, 060042, Bucharest, Romania

${ }^{2}$ University Politehnica of Bucharest, Department of Mechanics, 313 Splaiul Independenei, 060042, Bucharest, Romania

In this paper, the authors show a part of research works performed on the use of 3D scanners and 3D printers to execute plastic parts with complex surfaces. 3D scanning allows copying of certain surfaces in our environment, based on existing models. Scanned models may represent various objects, made of a wide range of materials: metals, ceramics, fabrics, plastics, leather, organic materials etc. [1]. This paper shows the results achieved using a scanner and a common and affordable - low-price - printer. 3D scanners and printers allow execution of clones of certain parts with irregular surfaces.
\end{abstract}

Keywords: 3D scanners, 3D printer, parts manufactured from plastics using 3D scanners and printers

Currently, the recent manufacturing methods [2,3], based on 3D-printing techniques, are used in various fields: industry, medicine, research etc [4].

3D scanning may lead to a digital caption of the spatial image of a piece. There are several methods for execution of this scan, but the method most commonly used today is the 3D Laser scanning method [5]. The size of scanned object, the work conditions, the scanning speed and accuracy are all dependent on the type of scanner used. Currently, a wide range of such scanners is available, starting from EUR 200 and up to several tens of thousands.

Several types of such scanners are shown below.

Figure 1 shows one of the most commonly used scanners.

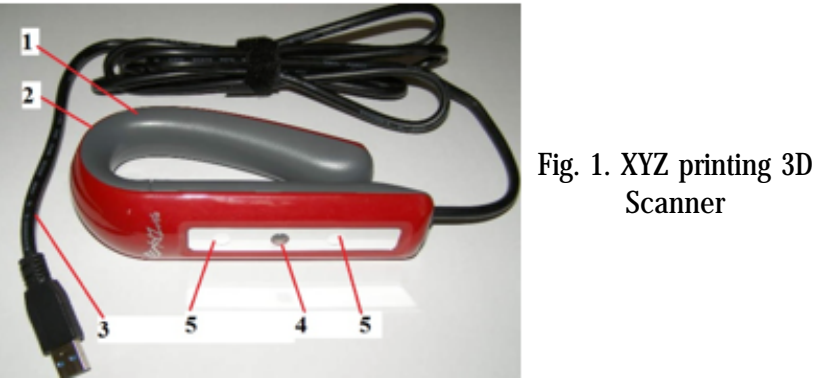

In figure 1, the following legend was used: 1 - handle, 2 - on/off switch, 3 - USB 3 power cable, 4 - photo camera, 5 - laser.

This scanner is connected to a laptop, and it may operate in three ranges:

Range 1 - objects with a maximum size of $600 \times 600 x$ $300 \mathrm{~mm}^{3}$,

Range 2 - objects with a maximum size of $400 \times 250 \times$ $400 \mathrm{~mm}^{3}$,

Range 3 - objects with a maximum size of $1000 \times 1000$ $\times 2000 \mathrm{~mm}^{3}$.

Whichever the range, it is recommended that the scanned object should not be smaller than $50 \times 50 \times 50$ $\mathrm{mm}^{3}$.

The scanning resolution is of $1-2.5 \mathrm{~mm}$.

Figure 2 shows a scanner with superior performances compared to the model above [5].

This scanner may be used for objects with minimum sizes of $200 \times 200 \times 200 \mathrm{~mm}^{3}$ and maximum sizes of 3000

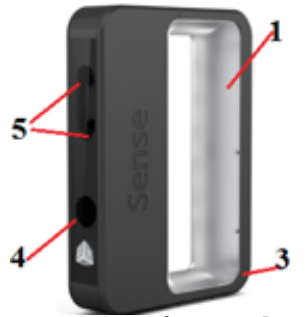

Fig. 2. Sense 3D Scanner

$\times 3000 \times 3000 \mathrm{~mm}^{3}$. Resolution of this scanner is of $0.9-1$ $\mathrm{mm}$.

The $2^{\text {nd }}$ generation of 3D Sense scanners uses the Intel Real Sense Technology, providing HD resolution of colors, which appear clearer and in higher details.

ARTEC 3D company manufactures high-performance 3D scanners, providing a 3D resolution of $0.1-0.5 \mathrm{~mm}$. These scanners are used in various industrial design applications, archeology, arts [5]. 1.

The scanner used by authors is the type shown in figure

\section{Experimental part}

Overview of objects scanned to be subsequently printed in $3 D$ with PLA filament

For $3 \mathrm{D}$ printing, the authors selected the items show $n$ in figure 3.

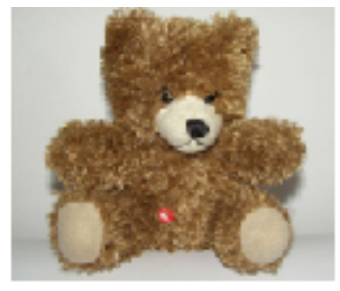

a loy

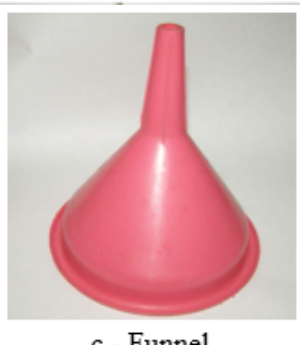

c - Funnel

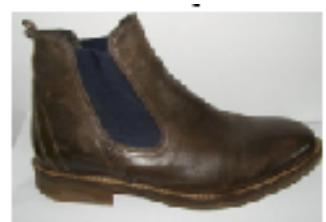

b Boul

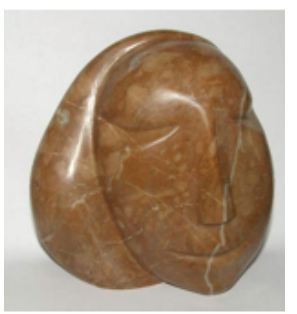

d - Statue
Fig. 3. Objects scanned to be subsequently printed in 3D with PLA filament 
Table 1

THE MAIN FEATURES OF OBJ ECTS

\begin{tabular}{|c|c|c|}
\hline OBJECT & $\begin{array}{c}\text { Actual sizes } \\
{\left[\mathrm{mm}^{3}\right]}\end{array}$ & Material \\
\hline The Toy & $144 \times 115 \times 140$ & FABRIC (Plush) \\
\hline The Boot & $311 \times 132 \times 174$ & Leather \\
\hline The Funnel & $99 \times 99 \times 111$ (rotation part) & Plastics \\
\hline The Statue & $126 \times 67.24 \times 124.94$ & Marble \\
\hline
\end{tabular}

Table 1 shows the main features of these objects.

\section{Overview of scanning results}

Scanning of objects above was performed using two special programs [5]. In both cases, the scan objectoption was used. Sizes of objects resulting following scans are shown in table 2.

It should be noticed that scanning was made in high accuracy conditions, size gaps being of maximum $1 \mathrm{~mm}$.

After scanning, editing of 3D models is made, and if necessary such models are corrected [5].

Table 3 shows the scanning results of these four objects.

\section{Determination of 3D printing parameters}

Currently, 3D printing has become a common method for the execution of various parts [6,7]. 3D plastic printers are manufactured by various companies at prices affordable even for small companies. For 3D printing, authors used a CTC DIY 3D PRINTER which is shown in figure 4 [8].

In figure 4, the following legend was used for the main elements of this printer: 1 - fixed frame, 2 -bed, 3- extruding
Table 2

SIZES OF SCANNED OBJECTS

\begin{tabular}{|c|c|}
\hline OBJECT & $\begin{array}{c}\text { Sizes resulted from scanning } \\
{\left[\mathbf{m m}^{\mathbf{3}}\right]}\end{array}$ \\
\hline The Toy & $144.278 \times 115.585 \times 140.282$ \\
\hline The Boot & $310.725 \times 134.513 \times 174.083$ \\
\hline The Funnel & $100.6 \mathrm{X} 101 \times 112$ (rotation part) \\
\hline The Statue & $125.42 \times 68.52 \times 122.4$ \\
\hline
\end{tabular}

unit, 4 - printer display. Work axes of this machine were noted with $X, Y$ and $Z$.

The following characteristic features of this printer must be noticed: maximum printing sizes $200 \times 200 \times 180 \mathrm{~mm}^{3}$, layer accuracy $0.1-0.5 \mathrm{~mm}$, nozzle diameter $0.4 \mathrm{~mm}$, maximum operating temperature $260^{\circ} \mathrm{C}$, work speed 35 $40 \mathrm{~mm} / \mathrm{s}$, fast speed mode $30-100 \mathrm{~mm} / \mathrm{s}$.

The material used for printing is PLA-type plastic filament with $1.75 \mathrm{~mm}$ diameter. The following temperatures were set for printing: $180^{\circ} \mathrm{C}$ - at extrusion head, $70^{\circ} \mathrm{C}$ - at the bed.

Objects achieved following printing shall be reduced to various scale models compared to items actuallyscanned.

Table 4 shows the sizes of objects scanned, and sizes of objects to be achieved.

\section{Results and discussions}

Objects achieved following 3D printing are shown in table table 5 . The same table also shows the actual sizes of objects measured after completion of the printing process.

In the printing process, the software program CURA was used on the CTC DIY 3D PRINTER

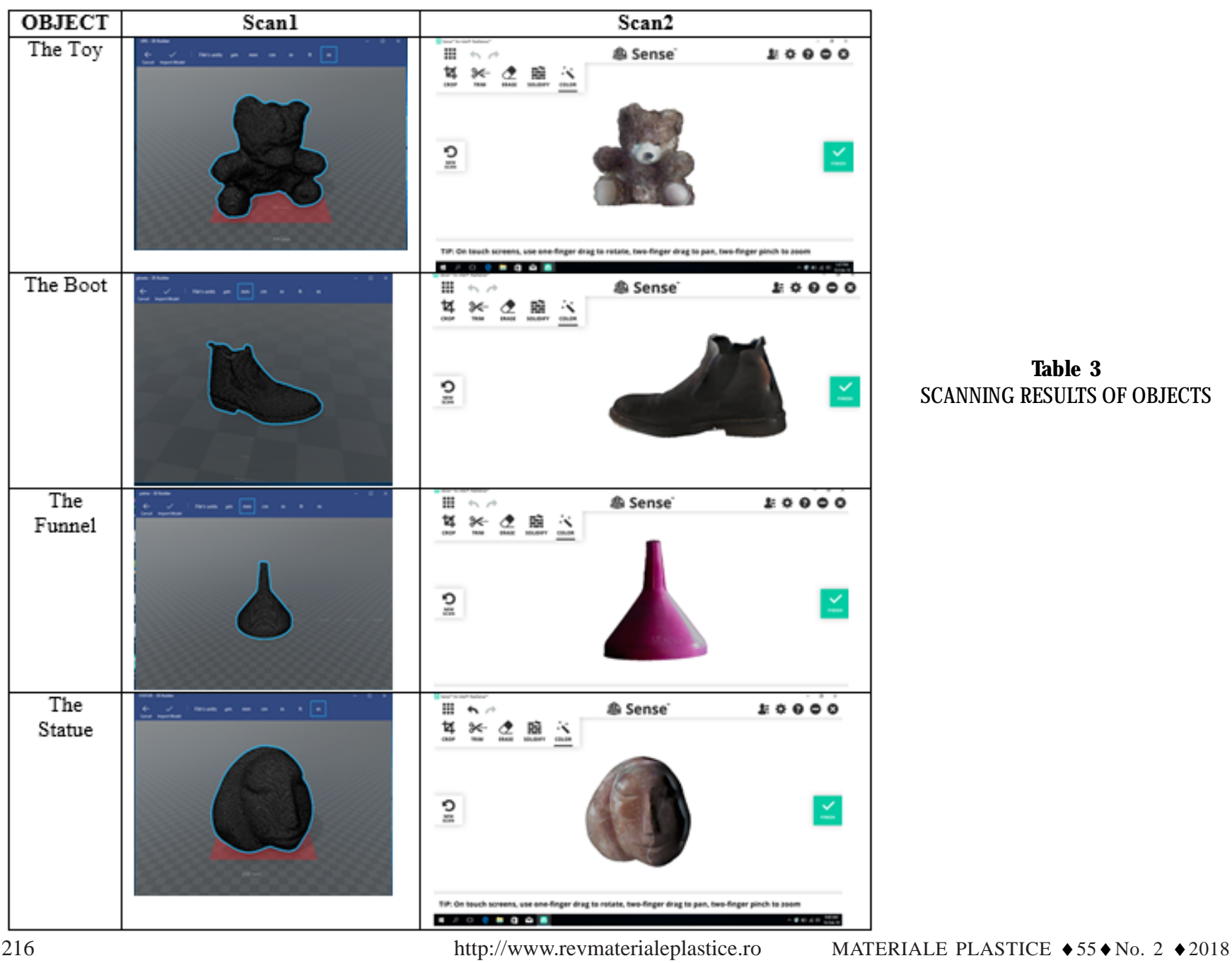


Table 4

ACHIEVED OBJ ECTS SIZES

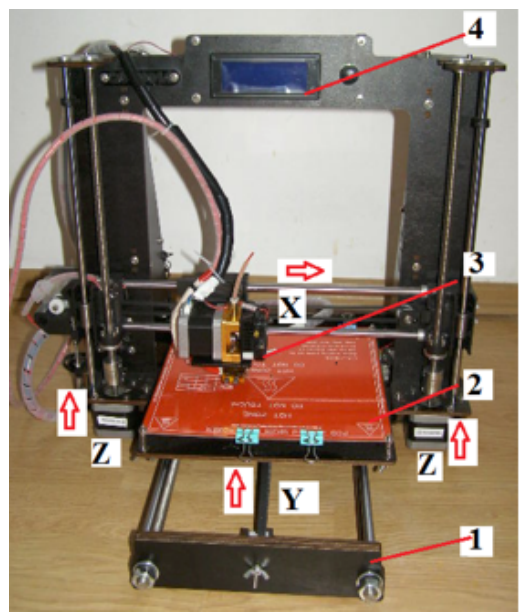

Fig. 4. CTC DIY 3D PRINTER

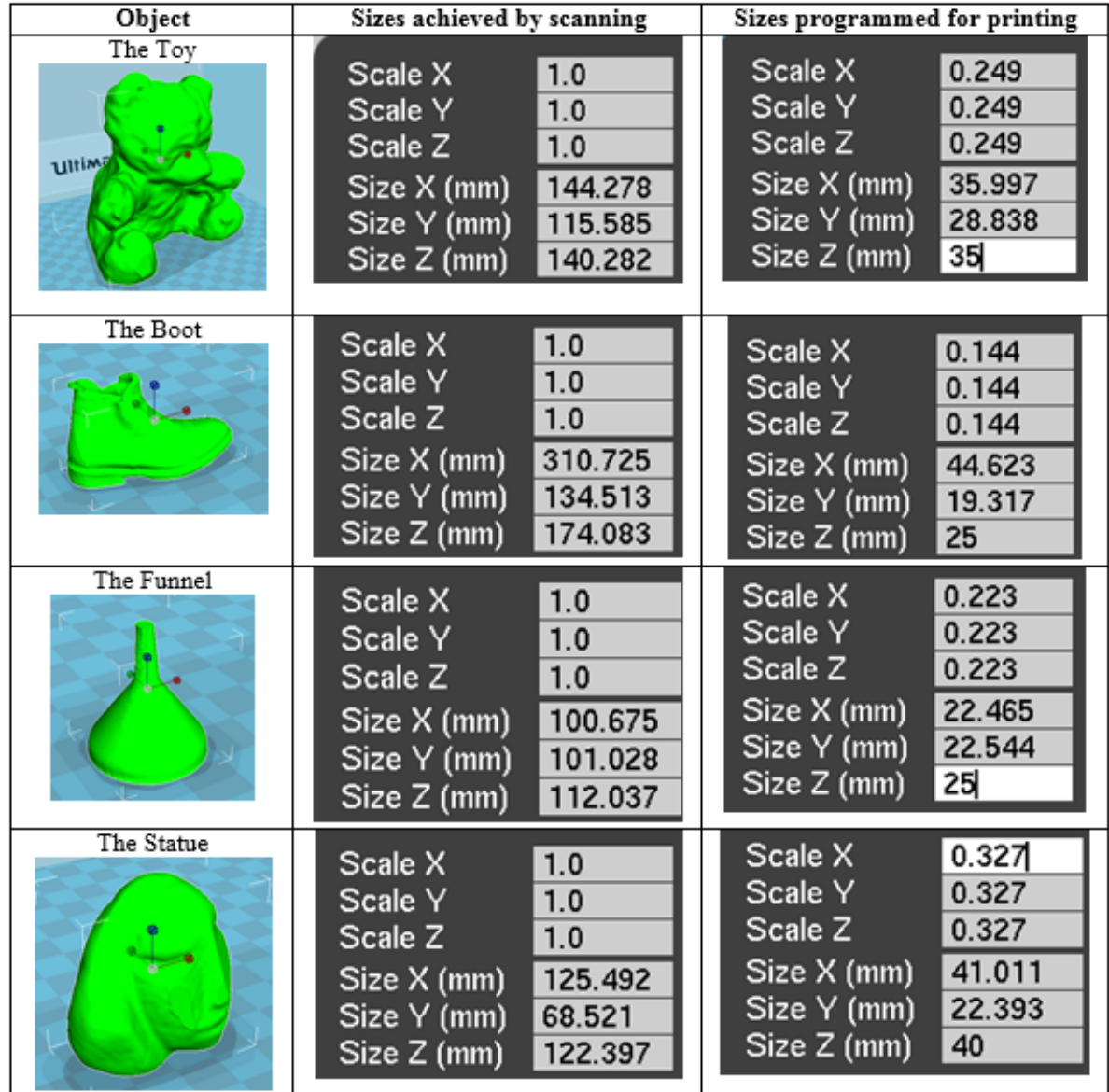

Table 5

3D PRINTING OB|ECTS ACHIEVED

\begin{tabular}{|c|c|c|}
\hline Object & Object achieved & $\begin{array}{c}\text { Sizes measured after } \\
\text { removal of burrs } \\
\text { [mm] }\end{array}$ \\
\hline The Toy & & $\mathrm{X}=34.8, \mathrm{Y}=27.5, \mathrm{Z}=35.8$ \\
\hline The Boot & & $\mathrm{X}=43.3, \mathrm{Y}=18 . \mathrm{Z}=24.7$ \\
\hline The Funne1 & & $\mathrm{X}=22.3, \mathrm{Y}=22 . \mathrm{Z}=25.15$ \\
& & $\mathrm{X}=40 . \mathrm{Y}=21.4, \mathrm{Z}=39.9$ \\
\hline The Statue & & \\
\hline & & \\
\hline
\end{tabular}

Below, for each object, the difference between the programmed size (achieved by scanning) and the size achieved by printing was calculated. Results are shown in table 6.

Table 6

THE DIFFERENCE OF SIZES

\begin{tabular}{|c|c|}
\hline Object & $\begin{array}{c}\text { Programmed size - size } \\
\text { achieved }=\Delta[\mathrm{mm}]\end{array}$ \\
\hline The Toy & $\Delta \mathrm{X}=1.2, \Delta \mathrm{Y}=1.3, \Delta \mathrm{Z}=-0.8$ \\
\hline The Boot & $\Delta \mathrm{X}=1.3, \Delta \mathrm{Y}=1.3, \Delta \mathrm{Z}=0.3$ \\
\hline The Funnel & $\Delta \mathrm{X}=0.1, \Delta \mathrm{Y}=0.5, \Delta \mathrm{Z}=0.15$ \\
\hline The Statue & $\Delta \mathrm{X}=1 . \Delta \mathrm{Y}=0.2, \Delta \mathrm{Z}=0.1$ \\
\hline
\end{tabular}


Size differences may be explained as follows:

- for the toy, due to its material, it is possible that in some areas the PLA filament with a diameter of $0.4 \mathrm{~mm}$ may nothave been laid properly, and removed as a burr;

- both for the toy and for the ice, layers are not laid continuously in the XOY plane, which may lead to occurrence of irregularities in this case;

- the extrusion temperature, the bed temperature and also the ambient temperature affect the printing accuracy also through the shrinking of material laid;

- sizes resulted from scanning may also include false information, beyond control, due to the 3D image capturing method.

\section{Conclusions}

3D scanning allows achievement of models that may be used in 3D printing with plastic filament (PLA). This material is easily available, at a price of app. EUR $20 / \mathrm{kg}$. [9]. Scanning may be made with various types of scanners. Currently, their price vary between EUR 200 and EUR 15,000 . Laser scanning is very accurate, allowing capture of complex spatial surfaces. As the scanner used by the authors hereof is one of the simplest models, it provided an acceptable scanning accuracy for outer surfaces that are not provided with counter-pieces. Size differences on the three axes, between measured and scanned values are of maximum $1 \mathrm{~mm}$. 3D scanning is influenced by the color and material of the scanned object, but also on its lighting method. It is recommended that scanning should be performed at low speed, and the scanned objectshould be placed on a flat surface and illuminated so that no shadows are formed. Usually, small adjustments are made after scanning.

After execution of the 3D capture, printing of desired objects may be performed. In case of the printer used by the authors, printing with PLA filament was made with size differences of up to $1.5 \mathrm{~mm}$ betw een capture and the printed object.
When scanned surfaces are surfaces destined for installation of a possible counter-piece, adjustments may be made. This may be achieved manually or with engraving machines.

\section{References}

1. GIGES, N. S., Top 10 Materials for 3D Printing, ASME.org, August 2014 https://www.asme.org/engineering-topics/articles/manufacturingprocessing/top-10-materials-3d- printing

2. GIBSON, I., ROSEN, D. W., STUCKER, B., Additive Manufacturing Technologies - Rapid Prototyping to Direct Digital Manufacturing, Publisher: Springer, New York, 2010

3. POPESCU, D., HADAR, A., COTET, C., Manufacturing of ABS P400 Solid Cellular Structures with Closed Cells By Fused Deposition Modeling as Rapid Prototyping Process, Mat. Plast., 43, no. 2, 2006, p. 175

4. POPESCU, D., ILIE, C., LAPTOIU, D., HADAR, A., BARBUR, R., Webbased Collaborative Platform for Personalized Orthopaedic Application, Studies in Informatics and Control, Vol. 25, No. 4, December 2016, pp. 517-526

5.***w w w.xyzprinting.com/en-US/product/3d-scanner-pro, www.3dsystems.com/shop/sense, www.artec3d.com/portable-3dscanners,www.ultimaker.com/en/resources/18803-cura-software

6. BIRD, J., (2012-08-08), Exploring the 3D printing opportunity. The Financial Times. Retrieved 2012-08-30

7. AUBREY, L. W., PEARCE, J. M., Distributed Manufacturing of Flexible Products: Technical Feasibility and Economic Viability, Technologies 2017, 5(4), 71

8. PRODAN, D., BUCURESTEANU, A., MOTOMANCEA, A., BALAN, E., Remanufacturing of heavy duty machine tools guideways plating with plastic materials, Mat. Plast., 53, no. 4, 2016, p. 599

9. GORDON, J., 3D Printer Creates Models that Save Time, Money, U.S. Air Force, Robins AFB Public Affairs, 30 January 2015, http:// www.af.mil/News/ArticleDisplay/tabid/223/Article/562920/3-d-printercreates-models-that-save-time-money.aspx

$\overline{\text { Manuscript received: } 17.01 .2018}$ 